prevalence of anemia was 90\%. Only two patients received nutritional support.

Conclusion Malnutrition in the hospital is common in Tunisia but remains under diagnosed and insufficiently supported. This entity deserves further study to determine its impact on health expenditures and to improve its screening and management.

\section{HOW MANY CALORIES ARE ENOUGH?}

Zrinka Šmuljićn ${ }^{*}$ Lana Omerza, Ivan Bambir, Eva Pavić, Ivana Todorić, Ivona Markelić, Andrea Vukić Dugac, Duška Tješić-Drinković. University Hospital Centre Zagreb

10.1136/archdischild-2021-europaediatrics.269

Because of disease complexity, it is challenging to realistically estimate energy needs of cystic fibrosis (CF) patients. During regular dietitian's check-ups, we noticed that CF patients who gained weight or maintained BMI targets consume more calories than are estimated as enough, following the ECFS and ESPEN guidelines. Therefore, we question if $100 \%$ increase of recommended energy intake is enough for some patients.

To support this doubt we calculated patients' energy needs based on Harris-Benedict formula and the level of physical activity, increased them following ESPEN guidelines and compared the recommended to actual intake and thriving.

Best example is a malnourished, picky-eater 12-year girl with poor appetite and impaired lung function (FEV1 29-43\% p.v.). The girl finally agreed to PEG tube in order to increase feeding possibilities when the BMI was $13 \mathrm{~kg} / \mathrm{m} 2$ (-3.03 SD) and FEV1 35\%p.v. At that point, her estimated energy needs were $1900 \mathrm{kcal}$ and according to ESPEN guidelines, the recommended intake was doubled. Because of poor food-intake $(1000-1500 \mathrm{kcal})$, this was achieved mainly through enteral nutritional supplements either orally or via PEG. She still didn't gain weight over a period of 9 months. During her last hospitalisation we reviewed the dietary approach. Her daily energy intake from food didn't surpass $1500 \mathrm{kcal}$ so we increased the enteral feeds to $5000 \mathrm{kcal}$ daily thus mounting energy intake to $\approx 6500 \mathrm{kcal} / 22.5 \mathrm{~kg}$. After the lung function stabilized again (FEV1 37\%p.v.), this high intake was necessary to retain weight gain. Following the same protocol at home, she gained $4 \mathrm{~kg}$ in a month (16.7\% of weight at discharge). Her BMI is now $15.3 \mathrm{~kg} / \mathrm{m} 2(-1.68 \mathrm{SD})$.

Our patient consumes $300-330 \%$ of energy needs of healthy peers. This example emphasizes the importance of the dietitian in the CF team, an individual approach to each patient and 'thinking out of the box'. Maybe it is time to revise the guidelines regarding energy requirements for $\mathrm{CF}$ patients.

\section{ACUTE ESOPHAGEAL NECROSIS IN A 15-YEAR OLD BOY - A CASE REPORT}

Lana Omerza*, Duška Tješić-Drinković, Irena Senečić-Čala, Mirna Natalija Aničić, Dinko Stančić-Rokotov, Jurica Vuković. University Hospital Center Zagreb, Croatia

\subsection{6/archdischild-2021-europaediatrics.270}

Acute esophageal necrosis (black esophagus, Gurvits syndrome) is a rare clinical entity which leads to upper gastrointestinal bleeding. First description dates to 1990, with around115 cases described in the literature. The condition has pathognomonic endoscopic appearance characterized by circumferential black mucosa in the distal esophagus, and discontinuing abruptly at the gastroesophageal junction. The pathogenesis is unclear, apparently multifactorial mucosal ischemia due to low flow vascular state or microvascular thrombosis is predisposing to topical damage by gastric content reflux. It's commonly seen in elderly men, with risk factors like diabetes, malignancy, alcohol consumption, shock, major surgery.

Diagnosis is made endoscopically.

Management requires hemodynamic stabilization, acid suppressive medication with avoidance of nasogastric tube placement. The condition has very poor prognosis, with mortality rate up to $35 \%$, and various complications including strictures and stenosis, perforation with mediastinitis and abscess formation.

Our patient, a 15 year old boy underwent surgery for scoliosis. During the immediate post surgical period he had hematemesis with consequent hemorrhagic shock. He was stabilized (IV fluids, packed red blood cells), nasogastric tube was inserted with evacuation of around $160 \mathrm{~mL}$ of blood and he was referred to our ICU. He required mechanical respiratory support and inotropic medications. Continuous parenteral PPI therapy was commenced.

Black, charcoal-like content was draining from the nasogastric tube, with further deterioration in hemoglobin levels.

Esophagogastroduodenoscopy showed black mucosa of lower esophagus, partly circumferential, partly linear, with cutoff at gastroesophageal junction.

There were no radiological signs of esophageal perforation, bilateral lung consolidates were surrounded by ground-glass interstitial changes.

Patient was kept NPO, on parenteral nutrition, with PPI and antibiotic treatment. He was weaned mechanical ventilation after three days, followed by brief stint of non-invasive respiratory support.

Unfortunately, significant stenosis with stricture formed in the area overlying initial necrosis. After several attempts of endoscopic ballon dilatation, refractory strictures reemerged. Surgical gastrostomy was performed to enable sufficient enteral caloric intake, and bring the patient to ideal physical condition for further treatment.

Planned colonic interposition surgery was not performed because of inadequate length of colon, hence thoracic surgeons performed retrosternal esophagogastroplasty Our patient had no further postoperative complications and was able to establish adequate oral feeding.

Acute esophageal necrosis should be considered as one of the causes of upper gastrointestinal bleeding, especially because its high mortality and complications rate requires immediate and aggressive early management.

\section{RISK FACTORS OF AUTOIMMUNE GASTRITIS IN CHILDREN WITH CELIAC DISEASE}

Natalia Shapovalova*, Valeria Novicova, Ksenia Klikunova, Ekaterina Orlova. Federal State budgetary Institute of Higher Education "Saint-Petersburg State Pediatric Medical University» of the Ministry of Health of the Russian Federation

10.1136/archdischild-2021-europaediatrics.271

The aim was to determine the risk factors of autoimmune gastritis (AG) in children with celiac disease (CD) Materials and 